\title{
Effects of Riboflavin on 6,7-Dimethyl-8-ribityllumazine Formation in Growing Cells of a Riboflavin-Adenine-Deficient Mutant, Bacillus subtilis
}

\author{
Kenji NAKAJIMA \\ Laboratory of Biochemistry, Faculty of Nutrition, Koshien University, 10-1 Momijigaoka, Takarazuka, \\ Hyogo 666-0006, Japan \\ (Received March 10, 2004)
}

\begin{abstract}
Summary The effects of riboflavin on the formation of 6,7-dimethyl-8-ribityllumazine (DMRL) were examined using the growing cells of a riboflavin, adenine deficient-mutant, Bacillus subtilis. The administration of low concentrations $(50-500 \mathrm{ng} / \mathrm{mL}$ ) of riboflavin to the basal medium significantly inhibited the formation of DMRL without any change in growth. Especially, the supplementation of more than $250 \mathrm{ng} / \mathrm{mL}$ riboflavin completely restricted the formation of DMRL under the experimental conditions. The results clearly indicate that a rigid negative feedback inhibition is operative for the biosynthetic pathway of riboflavin in B. subtilis.
\end{abstract}

Key Words 6,7-dimethyl-8-ribityllumazine, riboflavin, Bacillus subtilis, feedback inhibition

The biosynthetic mechanisms of riboflavin formation have been investigated using many microorganisms and various experimental methods for the past half century (1-3). The precursor and several pyrimidine intermediates on the biosynthetic pathway were isolated and identified in bacteria and fungi before 1980. Since then, the detailed reaction mechanisms between the primary intermediates have been further investigated (3).

The regulation of riboflavin formation has been reported in inhibition experiments related to iron with whole cells $(4,5)$ and crude enzymes $(6,7)$ from Pichia guilliermondii, and it is possible that it can be performed at any reaction step on riboflavin biosynthetic pathway by flavin mononucleotide (FMN) and/or flavin adenine dinucleotide (FAD) in B. subtilis $(8,9)$ and $P$. guilliermondii (10). Moreover, regulation was also reported at the levels of transcription and translation in the biosynthesis of riboflavin in bacteria (11) and fungus (12). Therefore, here I attempted to confirm the possibility of a negative feedback inhibition of riboflavin formation using a riboflavin-adenine double less-mutant of $B$. subtilis.

The reagents for fermenting of the microorganisms were purchased from Wako Pure Chemical Industries, Co., Ltd., Japan. The other chemicals used were of the best quality available. A riboflavin-adenine-deficient mutant, Bacillus subtilis AJ1988, was the gift of Ajinomoto Co., Ltd., Japan. The media and cultivation of $B$. subtilis were the same as in the previous paper (13).

The growth of the bacteria was expressed by the absorbance of a 31-fold diluted culture broth at $550 \mathrm{~nm}$ and specified times. After centrifugation, the amounts

E-mail: nakajima@koshien.ac.jp of formed DMRL were calculated by the absorbance of the 31 -fold diluted supernatant $\times 31 \times 1 / 10.2$ (molar extinction coefficient of DMRL) at $408 \mathrm{~nm}$, and expressed in terms of $\mathrm{mm}$. The $\mathrm{pH}$ values of the medium were measured with a Horiba pH meter (Mode F-23).

The riboflavin-adenine double-less mutant of $B$. subtilis proved to be lacking the riboflavin synthase reaction and to produce large amounts of the precursor of riboflavin, DMRL. This indicates the strong possibility that the inhibition of DMRL formation by the end product, riboflavin and its derivatives as such, is a negative feedback inhibition in the bacteria. Thus, the mutant cells were used in the present experiments.

The effects of the administration of various concentrations $(0-500 \mathrm{ng} / \mathrm{mL})$ of riboflavin to the basal medium on the growth, formation of DMRL and medium $\mathrm{pH}$ were examined $3 \mathrm{~d}$ after cultivation. The results are shown in Fig. 1. The growth reached a maximum at around $50 \mathrm{ng} / \mathrm{mL}$, and thereafter remained almost unchanged to the concentration of $500 \mathrm{ng} / \mathrm{mL}$. The formation of DMRL reached a maximum at $5 \mathrm{ng}$ / $\mathrm{mL}$ and thereafter rapidly decreased to the concentration of $50 \mathrm{ng} / \mathrm{mL}$, then the concentration was gradually reduced to $250 \mathrm{ng} / \mathrm{mL}$, at which time the formation of DMRL ceased completely. Over the lower concentration range of riboflavin, the maximal formation $(0.51 \mathrm{mM})$ of DMRL was detected at $5 \mathrm{ng} / \mathrm{mL}(0.013 \mathrm{~mm})$ riboflavin, and thereafter reduced to the amount of $0.22 \mathrm{mM}$ at $50 \mathrm{ng} / \mathrm{mL}(0.13 \mathrm{mM})$ riboflavin, which was sufficient for maximum growth. Thus, the bacteria appear to produce large amounts of DMRL. However, rigid negative feedback inhibition proved to function at the earlier stages of growth in the bacteria.

In contrast, the effects of 50 or $300 \mathrm{ng} / \mathrm{mL}$ riboflavin 


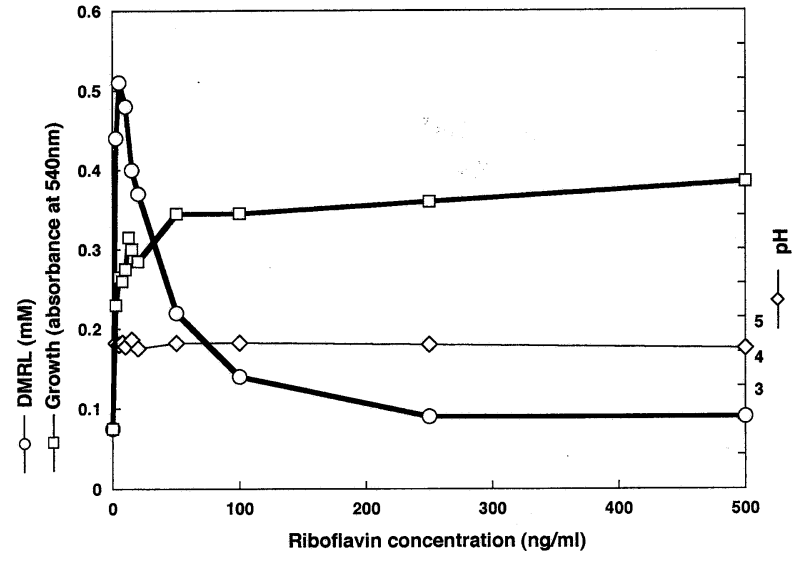

Fig. 1. Fluctuation of growth, riboflavin formation and medium $\mathrm{pH}$ with increasing concentrations of riboflavin. These parameters were determined on a basal medium with riboflavin ranging from 0 to $500 \mathrm{ng} / \mathrm{mL} 3 \mathrm{~d}$ after cultivation. For experimental conditions see details in the text.

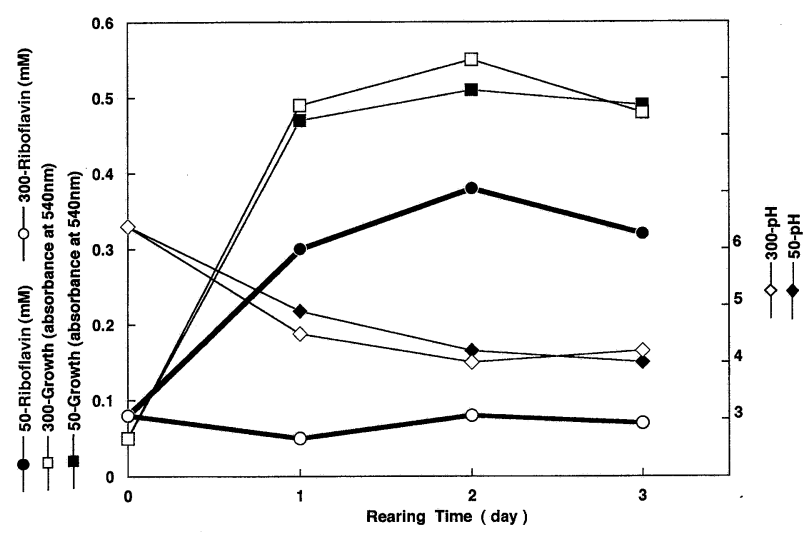

Fig. 2. Fluctuation of growth, riboflavin formation and medium $\mathrm{pH}$ with increasing culture times in presence of 50 or $300 \mathrm{ng} / \mathrm{mL}$ riboflavin. These parameters were determined on the basal medium containing 50 or $300 \mathrm{ng} / \mathrm{mL}$ riboflavin during the cultivation period for $3 \mathrm{~d}$. For experimental conditions see details in the text.

on the growth, DMRL formation and medium $\mathrm{pH}$ were examined during the cultivation period for $3 \mathrm{~d}$. The results are given in Fig. 2. The addition of 50 and $300 \mathrm{ng} / \mathrm{mL}$ riboflavin afforded almost no difference in growth and medium $\mathrm{pH}$, but both significantly changed the behavior of DMRL formation during the cultivation period for $3 \mathrm{~d}$, showing about $50 \%$ and $100 \%$ inhibition on the 3rd day as compared to the amounts of DMRL at the start of the experiments, respectively.

Therefore, the administration of more than $5 \mathrm{ng} / \mathrm{mL}$ riboflavin began to restrict the formation of DMRL, and that of more than $50 \mathrm{ng} / \mathrm{mL}$ riboflavin afforded almost no effect on growth but remarkably inhibited only DMRL formation. Moreover, the addition of more than $250 \mathrm{ng} / \mathrm{mL}$ riboflavin completely restricted only DMRL formation without any change in growth.

Accordingly, the present experiments with the grow- ing cells of $B$. subtilis provide a clear-cut result that the rigid negative feedback inhibition by riboflavin and/or its derivatives (FMN and FAD) is also operative for the riboflavin biosynthetic pathway in $B$. subtilis.

The elucidation of regulation mechanisms of riboflavin formation in B. subtilis is being investigated.

\section{Acknowledgments}

I sincerely appreciate Mr. Y. Yakushigawa for his skillful assistance with the experiments and Miss M. Sakamoto for her earnest assistance in the preparation of the manuscript.

\section{REFERENCES}

1) Brown GM, Williamson JM. 1987. 34. Biosynthesis of folic acid, riboflavin, thiamin, and pantothenic acid in Escherichia coli and Salmonella typhimurium (Neidhardt FC, ed), vol I, p 521-538, Washington, D. C.

2) Nakajima K. 2001. Elucidation of riboflavin biosynthesis for the past half century. ITE Lett 2: 560-569.

3) Bacher A, Eberhardt S, Eisenreich W, Fischer M, Herz S, Illarionov B, Kis K, Richter G. 2001. Biosynthesis of Riboflavin, in Vitamins and Hormones (Litwack G, ed), vol 61, p 1-49, Academic Press, San Diego, San Francisco, New York, London, Sidney, Tokyo.

4) Shavlovsky GM, Logvinenko EM, Struhovschchykova LM, Kashchenko VE. 1975. Biosynthesis of flavins and its regulation in the yeast Pichia gulliermondii. Ukr Biochem 47: 649-660.

5) Shavlovsky GM, Logvinenko EM, Schlee D, Koltun LV. 1976. Regulation of 6-hydroxy-2,4,5-triaminopyrimidine synthesis by riboflavin and iron in riboflavin-deficient mutants of Pichia guilliermondii yeast. Biochim Biophys Acta 428: 611-618.

6) Shavlovsky GM, Koltun LV, Kashchenko VE. 1978. Investigation of the regulation of activity of GTP-cyclohydrolase; the enzyme of the first stage of flavinogenesis in yeasts. Biochemistry 43: 1633-1639.

7) Logvinenko EM, Shavlovskii GM, Zakal'skii AE, Samarskii VA. 1989. Regulation of the activity and synthesis of enzymes participating in the formation of 6,7-dimethyl-8-ribityllumazine, a riboflavin precursor in yeast. Ukr Biochem 61: 30-35.

8) Coquard D, Huecas M, Ott M, Dijil JM, Loon APGM, Hohmann H. 1997. Molecular cloning and characterization of the ribC gene from Bacillus subtilis: A point mutation in ribC results in riboflavin overproduction. Gen Genet 254: 85-92.

9) Mack MA, Loon PGM, Hohman H-P. 1998. Regulation of riboflavin biosynthesis in Bacillus subtilis is affected by the activity of the flavokinase/flavin adenine dinucleotide synthetase encoded by ribC. J Bacteriol 180: 950955.

10) Stenchuk NN, Kutsiaba VI, Kshanovskaia BV, Fedorovich DV. 2001. Effect of rib83 mutation on riboflavin synthesis and iron acquisition in the yeast Pichia guilliermondii. Microbiology 70: 647-651.

11) Vitreschak AG, Roionov DA, Mironov AA, Gelfand MS 2002. Regulation of riboflavin biosynthesis and transport genes in bacteria by transcriptional and translational attenuation. Nucleic Acids Res 30: 3141-3151.

12) Schlosser T, Schmidt G, Stahmann KP. 2001. Transcrip- 
tional regulation of 3,4-dihydroxy-2-butanone 4-phosphate synthase. Microbiology 147: 3377-3386.

13) Mitsuda H, Nakajima K, Yamada, Y. 1978. Isolation of
4-(1'-D-ribitylamino)-5-amino-2,6-dihydroxypyrimidine from a riboflavin-adenine-deficient mutant of Bacillus subtilis. J Biol Chem 253: 2238-2243. 